\begin{tabular}{|c|c|c|}
\hline & International Journal of Current Research in & \\
\hline & Biosciences and Plant Biology & anto \\
\hline $\begin{array}{l}\text { EXCELLENT } \\
\text { PUBLISHERS } \\
\end{array}$ & Journal homepage: www.ijcrbp.com & \\
\hline
\end{tabular}

\title{
Molecular Cloning and Sequence Analysis of MADS-Box Family Gene (GbMADS6) from Ginkgo biloba L.
}

\author{
Yang Wan, Jia-Bao Ye, Guiyuan Wang, Weiwei Zhang*, Feng Xu and Yongling Liao \\ College of Horticulture and Gardening, Yangtze University, Jingzhou 434025, China \\ *Corresponding author.
}

\begin{abstract}
Based on the results of our research group study on gingko using RNA-seq technology, a full-length cDNA sequence of MADS-box gene from Ginkgo biloba was cloned by RT-PCR, which named as GbMADS6 (GenBank accession no. KX061105). The GbMADS6 contains a 735 bp open reading frame(ORF) corresponding to a deduced protein of 245 amino acids, while the estimated isoelectric point (pI) and molecular weight of the putative protein were 5.13 and $59.67 \mathrm{kDa}$, which had a typical MADS-box domain. Homology analysis indicated that the deduced GbMADS6 protein was highly homologous to other MADS-box Proteins from different species, especially with Lolium perenne MADS4 and Sorghum bicolor MADS1 identities up to 81\%. Predicted protein secondary structure showed that GbMADS6 protein contents of the structure with $51.84 \%$ of alpha helix $(\mathrm{Hh})$, extended strand $(\mathrm{Ee})$ of $15.10 \%$, random coil $(\mathrm{Cc})$ of $6.94 \%$ and beta turn (Tt) of $26.12 \%$. Phylogenetic analysis showed that GbMADS6 has a closer relationship with Pinus tabuliformis MADS protein than with other MADS-box proteins. Those results suggest that GbMADS6 belongs to MADS-box super family and may be involved in regulating the development of the flower.
\end{abstract}

\section{Article Info}

Accepted: 20 April 2016

Available Online: 06 May 2016

Ke y w o r d s

Ginkgo biloba

MADS-box

Molecular cloning

Sequence analysis

\section{Introduction}

Ginkgo biloba L., commonly called maidenhair or sun tree, is a dioecious tree native to China. Often described as a "living fossil", it is the world's oldest relic plant. Conventional breeding plays a limited role in this program because ginkgo has characteristics such as highly long juvenile period, complex genetic background as well as usually blossoms and bears fruit 15 to 20 years after growing. Therefore, how to promote blossom of seedling and shorten of the juvenile period on ginkgo development is necessary. MADS gene was an essential gene involved in the photoperiod pathway controlling plant flowering time. MADS genes have been cloned from many plants, such as apple (Sung et al., 2000), Arabidopsis (Tapia-
López et al., 2008), citrus (Endo et al., 2006), peach (Bielenberg et al., 2008), mango (Pacheco-Sánchez et al., 2014) and tomato (Martel et al., 2011).

The key step of the flowering process was linked to the inflorescence primordium formation and floral organ differentiation, and then the formation of its floral organ have the reproductive functions, of certain shape and specific order of space (Bernier et al., 1974). As a kind of transcription factors, MADS-box gene played a very important role in kinds of cellular processes, especially in the development of floral organs (Shore and Sharrocks, 1995). The ABC model illustrated the molecular mechanism of floral organ development, and explained the floral organ mutants of homeotic gene (Weigel et al., 1994), after Theissen 
et al. (2000) structured the latest advances in the genetic ABCDE model of floral organ development. Basing on the ABCDE model, the expression of class A genes command sepal formation and petal development, class B gene activities specifies the development of petals and stamens. In this same way, class $\mathrm{C}$ gene expression specifies stamen and pistil formation in the blossom, class $\mathrm{D}$ genes determine ovule development, while class $\mathrm{E}$ and $\mathrm{ABC}$ gene activities regulate the development of floral organ (Adam et al., 2007).

The MADS-box gene was a kind of specific regulation of gene family and widely present in plants, which encode proteins were classification transcription factor. MADSbox genes had a highly conserved DNA binding domain that was a MADS box (Heuer et al., 2000), the MADSbox gene was identified and bound downstream target specific sites, through the binding domain, aimed at regulating the expression of target genes (Jack et al., 1992). The MADS-box gene was the main control factor of the development process, experimental investigation showed that MADS-box gene family were not just regulation of floral organ development, in addition, MADS-box gene in the control of the time of flowering, determine of tissue differentiation (Weigel et al., 1995), control of embryonic development (Perry et al., 1996), promote the formation of root (Purugganan, 1997) and regulate the development of seeds (Ohad et al., 1996) and fruits (Gu et al., 1998) played an important role. In recent years, the research emphasis was on MADS-box gene regulation of reproductive growth, understanding the regulation of the plant from the vegetative to reproductive growth process has important significance for control the growth and development of a flowering plant. The molecular mechanism of floral organ development is a hotspot in plant developmental biology researches. In this study, we characterized the MADS6 gene from the Ginkgo biloba for the first time, and GbMADS6 might have played a significant role in the regulation of ginkgo flowering.

\section{Materials and methods}

\section{Plant materials}

Twenty-year-old grafts of Ginkgo biloba were grown in an orchard at Yangtze University, in China. The flowers were collected, immediately put into liquid nitrogen, and kept at Ultra-Low Temperature Freezer-Uplight type (DW-86L729, Haier Co. Ltd., China) prior to total RNA extraction.

\section{RNA extraction and isolation of GbMADS6}

Total RNA was isolated from frozen plant tissues using the CTAB method (Cai et al., 2007). The products of total RNA were separated on $1.5 \%$ agarose gel (Sangon Biotech, Shanghai, Co. Ltd.) stained with ethidium bromide. The process for inverse transcription of cDNA through reverse transcriptase byusing PrimeScript ${ }^{\mathrm{TM}} 1 \mathrm{st}$ Strand cDNA Synthesis Kit (TaKaRa, Dalian, China) with RNA as a template. The specific primer GbMADS6-F ( 5 '-AGGTGCAGTACCGTTTCTGTGTGC-3') and reverse primer GbMADS6-R (5'-TTTTTTTCTA CCAAGAAAGT CATTAGCG-3') were designed with the EST sequence of the Ginkgo MADS6 gene. The PCR reaction was carried out in a final volume of $50 \mu \mathrm{l}$ with a reaction mixture containing $2 \mu \mathrm{l}$ cDNA products, $5.0 \mu \mathrm{l}$ 10xbuffer, $4.0 \mathrm{mmol} \mathrm{l}^{-1} \mathrm{MgCl}_{2}, 1.0 \mu \mathrm{l}$ TaqDNA polymerase, $1.0 \mu \mathrm{dNTP} \operatorname{mix}\left(10 \mathrm{mmol} \mathrm{l}^{-1}\right)$ and $33.5 \mu \mathrm{l}$ $\mathrm{ddH}_{2} \mathrm{O}$ up to $50 \mu \mathrm{l}$. The reaction was performed at $95^{\circ} \mathrm{C}$ for $3 \mathrm{~min}$, and then subjected to 34 cycles of $95^{\circ} \mathrm{C}$ for $20 \mathrm{~s}$, $58^{\circ} \mathrm{C}$ for $30 \mathrm{~s}$ and $72^{\circ} \mathrm{C}$ for $90 \mathrm{~s}$, plus a final extension at $72^{\circ} \mathrm{C}$ for $10 \mathrm{~min}$. The amplified products were analysed by $1 \%$ gel electrophoresis and purified by a AxyPrep DNA Gel Extraction Kit. The purified product was cloned into the pMD18-T vector (Dalian TaKaRa, China), and then sequenced (Sangon Biotech. Shanghai Co. Ltd.).

\section{Bioinformatic analysis}

Protein and DNA homology searches were performed by using the BLAST program in website (http://www.ncbi.nlm.nih.gov/). Multiple sequence alignment was performed by using the website http://multalin.toulouse.inra.fr/multalin/. Phylogenetic analysis of GbMADS6 from ginkgo and other MADS from other plants was performed by using software Clustal X 2.0 and MEGA6.0, The dependability of the tree was determined by bootstrap analysis with 1000 replicates.

\section{Results}

\section{cDNA cloning of GbMADS6}

Based on the sequences of EST, the full-length cDNA fragment of GbMADS6 was amplified by PCR using a pair of specific primer. The length of the cDNA sequence of GbMADS6 is $1291 \mathrm{bp}$ (GenBank accession no. KX061105), and the open reading frame is $735 \mathrm{bp}$ encoding 245 amino acids (Fig. 1). The cDNA sequence of GbMADS6 had high similarity with other MADS-box genes, and the $\mathrm{G}+\mathrm{C}$ content of GbMADS6 sequence is $42.8 \%$. 


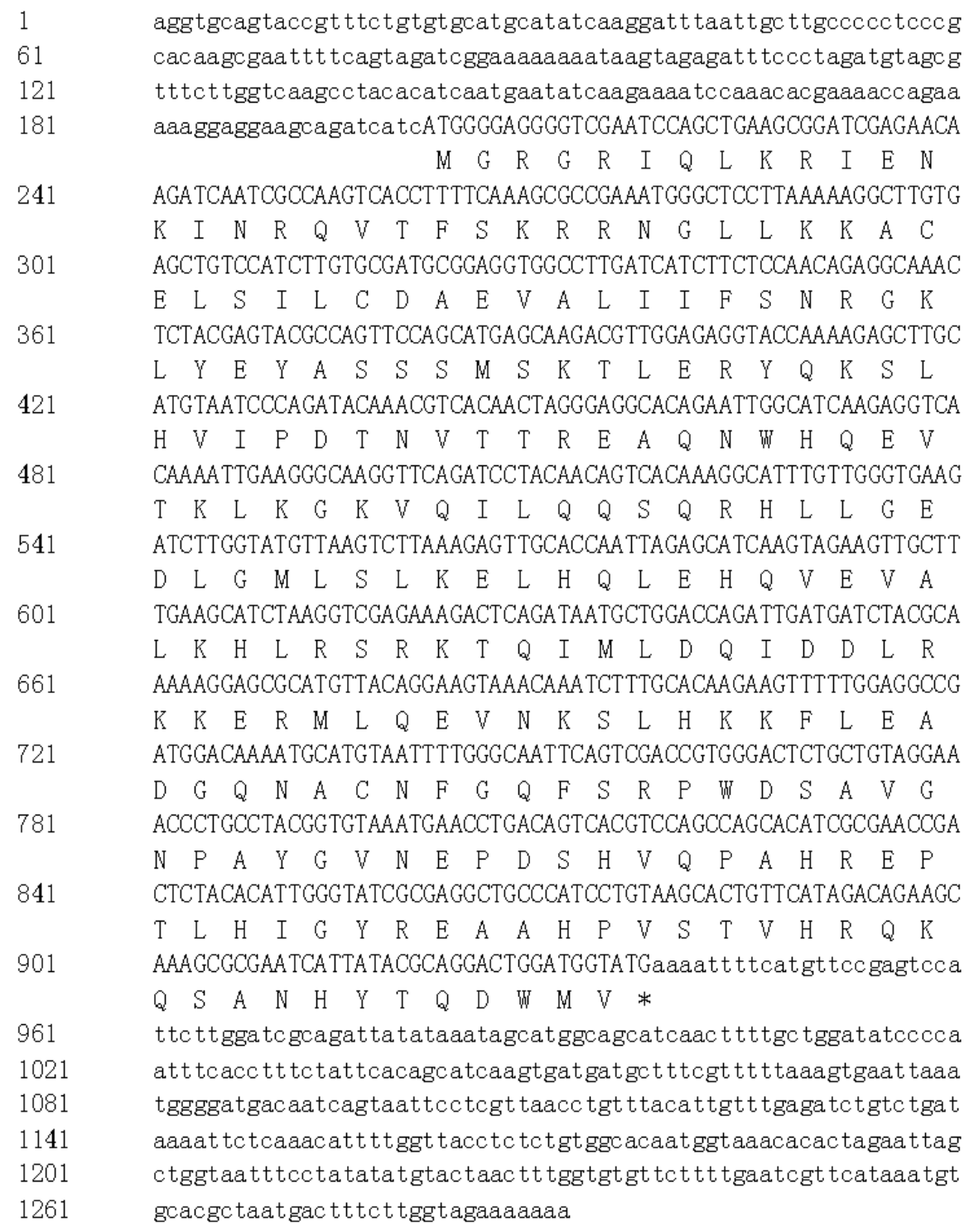

Fig. 1: The nucleotide acid sequence and deduced amino acid sequence of GbMADS6.

\section{Characterization of the deduced GbMADS6 protein}

Through analysis with the Computer $\mathrm{pI} / \mathrm{Mw}$ (http://web.expasy.org/compute_pi/), we found the molecular weight and isoelectric point of predicted GbMADS6 amino acid were 5.13 and $59.67 \mathrm{kDa}$, respectively. Blastp aligning analysis found the deduced GbMADS6 protein has MADS_MEF2_like, K-box region, and conserved MADS-box domain. The cloned
GbMADS6 belongs to MADS super family. The secondary structures of MADS proteins were predicted by using SOPMA tool. It was found that GbMADS6 contents extensive alpha helix (Hh) $51.84 \%$, extended strand (Ee) $15.10 \%$, random coil (Cc) $6.94 \%$ and beta turn (Tt) $26.12 \%$ (Fig. 2). The secondary structures of deduced GbMADS6 had high similarities with Lilium formosanum and Dendrocalamus latiflorus MADS-box proteins (Table 1).

Table 1. Secondary structure of MADS6 proteins (unit: \%).

\begin{tabular}{lllll}
\hline Species & Alpha $(\mathbf{H h})$ & Extended strand (Ee) & Random coil (Cc) & Beta turn (Tt) \\
\hline Ginkgo biloba & $51.84 \%$ & $15.10 \%$ & $6.94 \%$ & $26.12 \%$ \\
Lilium formosanum & $55.37 \%$ & $11.98 \%$ & $8.68 \%$ & $23.97 \%$ \\
Dendrocalamus latiflorus & $54.92 \%$ & $17.21 \%$ & $8.61 \%$ & $19.26 \%$ \\
\hline
\end{tabular}

Y. Wan et al. (2016) / Molecular Cloning and Sequence Analysis of MADS-Box Family Gene (GbMADS6) from 

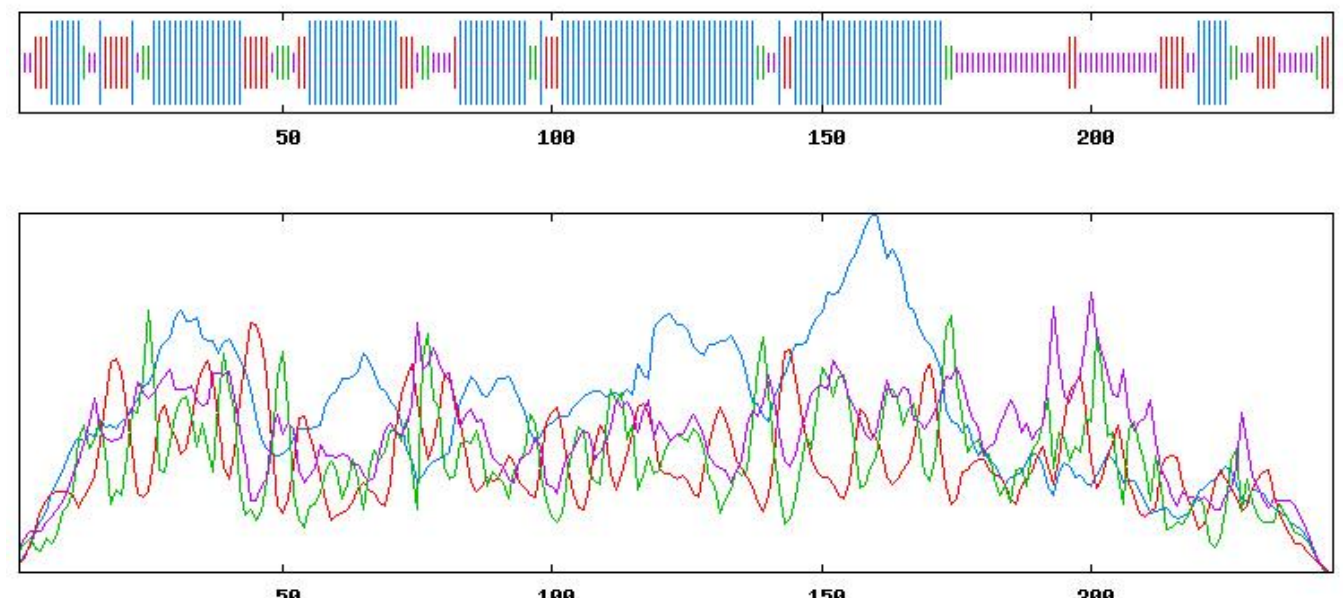

Fig. 2: The predicted secondary structures of GbMADS6 protein.

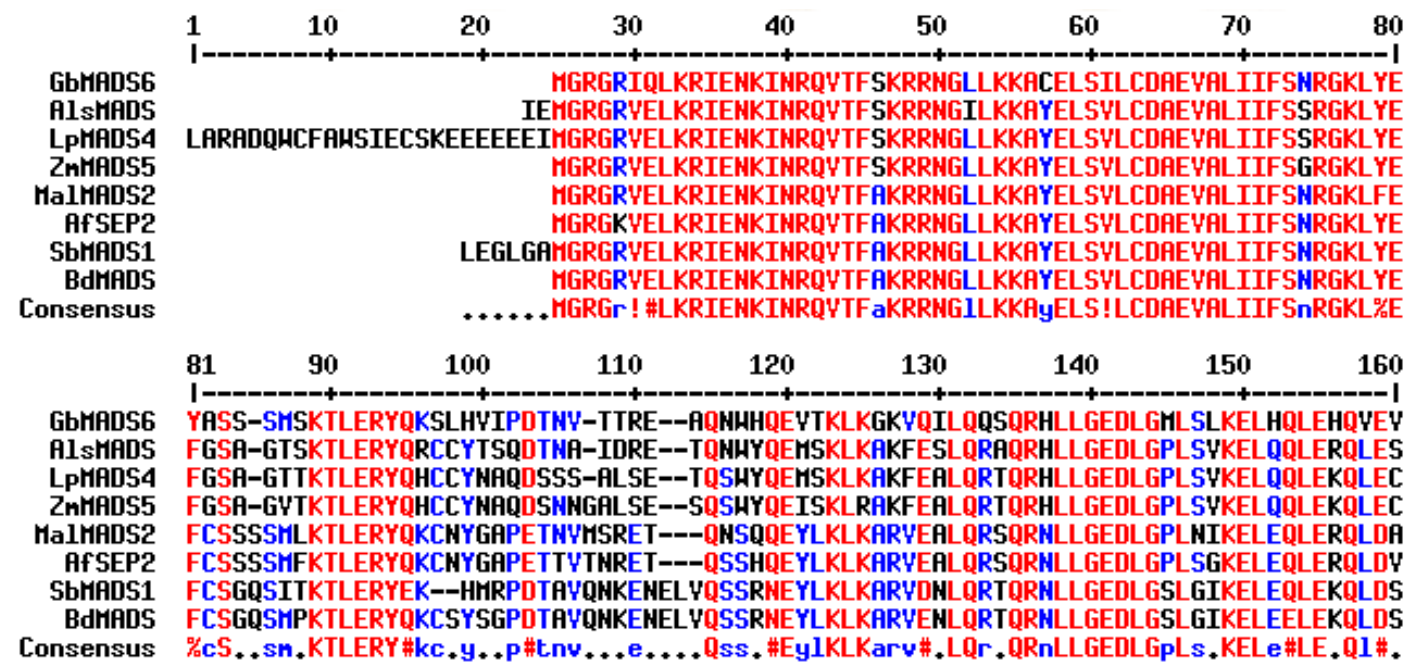

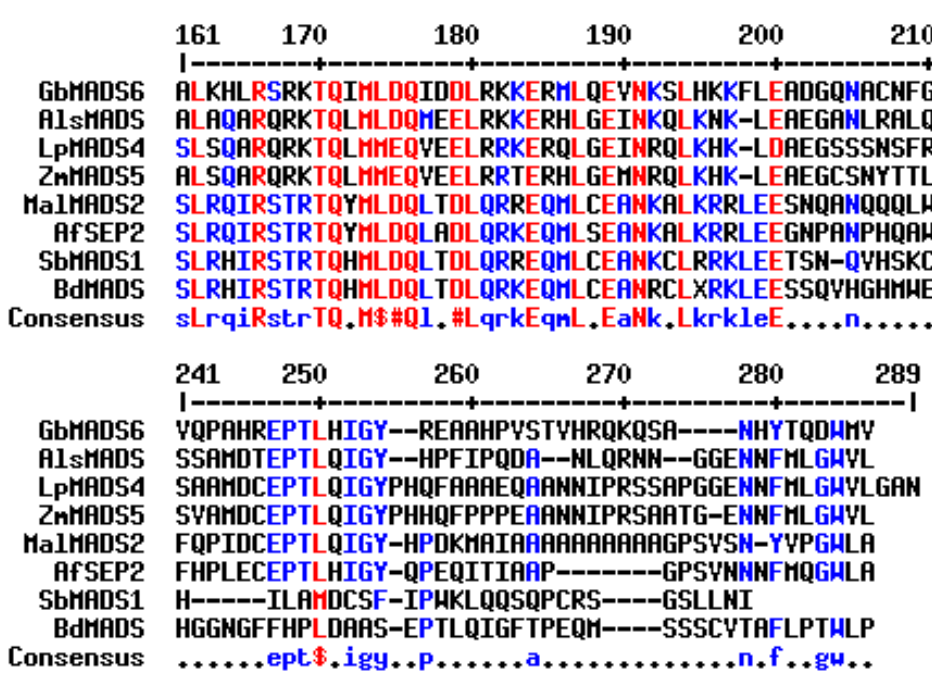

Fig. 3: The homology comparison of GbMADS6 amino acid sequence with other plant MADS proteins. Alstroemeria ligtu subsp. MADS (AB694896.1); Musa acuminata MADS2 (KM261780.1); Lolium perenne MADS4 (AY198329.1); Sorghum bicolor MADS1 (U49734.1); Zea mays MADS5 (KJ726929.1); Aristolochia fimbriata MADS1 (KT957081.1); Brachypodium distachyon MADS (HQ588325.1). High consensus is indicated in red colour (default: 90\%); low consensus is indicated in blue colour (default: 50\%, must be less than first value); non-similar amino acids are indicated with black colour; white is the background colour. 


\section{Multiple alignments of GbMADS6 protein}

Sequence comparison analyses by Blast $\mathrm{P}$ Search (http://www.ncbi.nih.gov) showed that GbMADS6 had higher homology with other MADS proteins. The amino acid sequences multiple sequence alignment showed that GbMADS6 had high identities with Alstroemeria ligtu subsp. MADS (73\% identities, AB694896.1), Musa acuminata MADS2 (79\% identities, KM261780.1), Lolium perenne MADS4 (81\% identities, AY198329.1), Sorghum bicolor MADS1 (81\% identities, U49734.1), Zea mays MADS5 (80\% identities, KJ726929.1), Aristolochia fimbriata MADS1 (78\% identities, KT957081.1) and Brachypodium distachyon MADS (77\% identities, HQ588325.1) (Fig. 3). All of the data mentioned above indicate that GbMADS6 was a member of the MADS family.

\section{Molecular evolution analysis of MADS proteins}

In order to study the evolutionary relationships between GbMADS6 and MADS proteins from other plant species, a phylogenetic tree was constructed by using MEGA 6.0. Phylogenetic analysis of MADS showed that GbMADS6 have a closer relationship to Pinus tabuliformis MADS protein than to other MADS-box proteins.

As shown in Fig. 4, the GbMADS6 protein together with Alstroemeria ligtu subsp., Lolium perenne, Zea mays and Setaria italica were grouped into a functional cluster. From the above results, it can be suggested that GbMADS6 belonged to MADS-box gene families, GbMADS6 may have similar functions with other MADS proteins of the same branch.

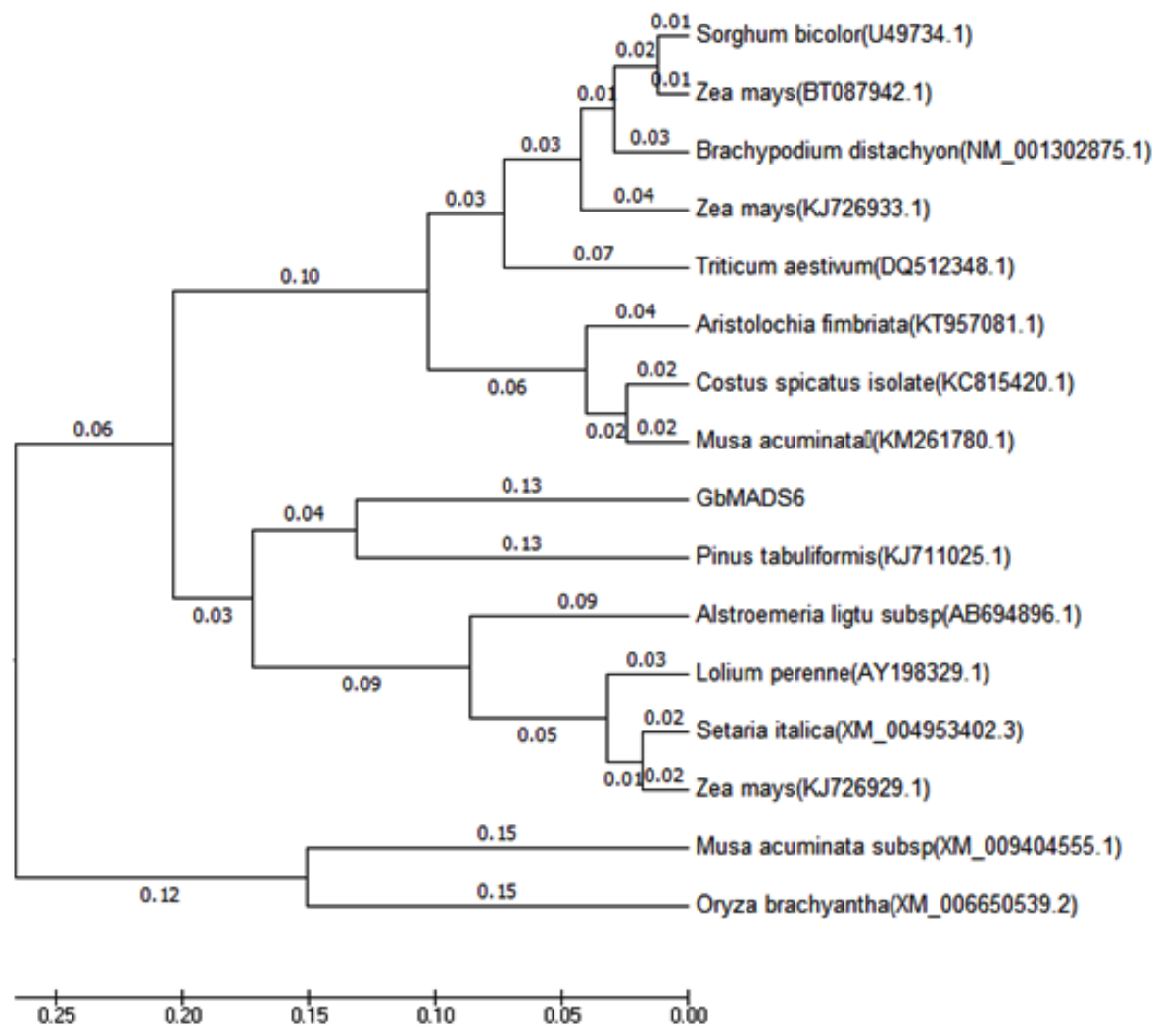

Fig. 4: Phylogenetic tree of MADS amino acid sequences from Ginkgo biloba and other plant species. The numbers at each node represent the bootstrap values (with 1,000 replicates).

\section{Discussion}

MADS-box gene family played an important role in controlling flower development, the gene family had a conservative DNA-binding domain (MADS-box). The functional diversity within MADS-box genes, not only determined the meristem and floral organ specificity, but also involved in regulation of vegetative growth, ovary development, formation of the root, completion of the embryo morphological, and the gene expression is also associated with resistance (Liljegren et al., 2000). Most MADS-box genes participate in different phases of floral 
development and form a complicated gene regulating network with each other to determine the characteristics of a flower's primordium and organs.

MADS-box gene family is divided into type I and type II genes according to sequence and structure characteristics (Alvarez-Buylla et al., 2000).Type I genes functions are still not clear in plants and in the current research, expression patterns and function of type II genes are known (De Bodt et al., 2003). Type II genes contain MADS (M), Intervening (I), Keratin-like (K) and C-terminal (C) inordinately of conservative domain, it was also known as the MIKC-type (Nam et al., 2004). MADS-box gene GbMADS6 was amplified from ginkgo by RT-PCR. Sequence analysis indicated that its coding region was $735 \mathrm{bp}$, with an open reading frame encoding 345 amino acids, which displayed the structure of a typical plant MADS-box gene, including $\mathrm{M}, \mathrm{I}, \mathrm{K}$ and $\mathrm{C}$ area, consequently, GbMADS6 gene attributed to MIKC type. It is inferred that GbMADS6 might adjust the differentiation process of flower and fruit development in Ginkgo biloba. The genetic transformation of GbMADS6 in tobacco is in progress by Agrobacterium-mediated transformations for functional identification of GbMADS6 gene.

\section{Conclusion}

GbMADS6 with an ORF about 735bp, encoding 245 amino acids was isolated by RT-PCR from ginkgo. The amino acids of GbMADS6 contain a conserved MADSbox domains and displays extensive homology to MADS amino acids from other plants that will enable us to conclude the flower development model of Ginkgo biloba. The phylogenetic tree analysis demonstrated the GbMADS6 protein was grouped with Pinus tabuliformis. The GbMADS6 is likely to participate in regulating the differentiation process of flower and fruit development in Ginkgo biloba.

\section{Conflict of interest statement}

Authors declare that they have no conflict of interest.

\section{Acknowledgement}

This present work was supported by the National Natural Science Foundation of China (31300574), the Key Scientific Research Program of Chinese Ministry of Education (212112 and 210137) and the Youth Talent Foundation of Hubei Province (2013CFA039).

\section{References}

Adam, H., Jouannic, S., Orieux, Y., Morcillo, F., Richaud, F., Duval, Y., Tregear, J.W., 2007. Functional characterization of MADS box genes involved in the determination of oil palm flower structure. J. Exp. Bot. 58(6), 1245-1259.

Alvarez-Buylla, E.R., Liljegren, S.J., Pelaz, S., Gold, S.E., Burgeff, C., Ditta, G.S., Yanofsky, M.F., 2000. MADSbox gene evolution beyond flowers: expression in pollen, endosperm, guard cells, roots and trichomes. Plant J. 24(4), 457-466.

Bernier, G., Kinet, J.M., Bodson, M., Rouma, Y., Jacqmard, A., 1974. Experimental studies on the mitotic activity of the shoot apical meristem and its relation to floral evocation and morphogenesis in Sinapis alba. Bot. Gazette. 345-352.

Bielenberg, D.G., Wang, Y.E., Li, Z., Zhebentyayeva, T., Fan, S., Reighard, G.L., Abbott, A.G., 2008. Sequencing and annotation of the evergrowing locus in peach [Prunus persica (L.) Batsch] reveals a cluster of six MADS-box transcription factors as candidate genes for regulation of terminal bud formation. Tree Genet. Genomes. 4(3), 495507.

Cai, R., Xu, F., Chen, L., Cheng, S., 2007. Modification of total RNA isolation method from different Ginkgo biloba organs. Biotechnol. 17(4), 38-41.

De Bodt, S., Raes, J., Van de Peer, Y., Theißen, G., 2003. And then there were many: MADS goes genomic. Trends Plant Sci. 8(10), 475-483.

Endo, T., Shimada, T., Fujii, H., Omura, M., 2006. Cloning and characterization of 5 MADS-box cDNAs isolated from citrus fruit tissue. Sci.Hortic. 109(4), 315-321.

Gu, Q., Ferrándiz, C., Yanofsky, M.F., Martienssen, R., 1998. The FRUITFULL MADS-box gene mediates cell differentiation during Arabidopsis fruit development. Dev. 125(8), 1509-1517.

Heuer, S., Lörz, H., Dresselhaus, T., 2000. The MADS box gene ZmMADS2 is specifically expressed in maize pollen and during maize pollen tube growth. Sex. Plant Reprod. 13(1), 21-27.

Jack, T., Brockman, L.L., Meyerowitz, E.M., 1992. The homeotic gene APETALA3 of Arabidopsis thaliana encodes a MADS box and is expressed in petals and stamens. Cell. 68(4), 683-697.

Liljegren, S.J., Ditta, G.S., Eshed, Y., Savidge, B., Bowman, J.L., Yanofsky, M.F., 2000. SHATTERPROOF MADSbox genes control seed dispersal in Arabidopsis. Nature. 404(6779), 766-770.

Martel, C., Vrebalov, J., Tafelmeyer, P., Giovannoni, J.J., 2011. The tomato MADS-box transcription factor RIPENING INHIBITOR interacts with promoters involved in numerous ripening processes in a COLORLESS NONRIPENING-dependent manner. Plant Physiol. 157(3), 1568-1579.

Nam, J., Kim, J., Lee, S., An, G., Ma, H., Nei, M., 2004. Type I MADS-box genes have experienced faster birth-and- 
death evolution than type II MADS-box genes in angiosperms. Proc. Natl. Acad. Sci. USA. 101(7), 19101915.

Ohad, N.I.R., Margossian, L., Hsu, Y.C., Williams, C., Repetti, P., Fischer, R.L., 1996. A mutation that allows endosperm development without fertilization. Proc. Natl. Acad. Sci. 93(11), 5319-5324.

Pacheco-Sánchez, M.A., Contreras-Vergara, C.A., HernandezNavarro, E., Casas-Flores, S., Islas-Osuna, M.A., 2014. Molecular modeling and expression analysis of a MADSbox cDNA from mango (Mangifera indica L.). 3 Biotech. 4(4), 357-365.

Perry, S.E., Nichols, K.W., Fernandez, D.E., 1996. The MADS domain protein AGL15 localizes to the nucleus during early stages of seed development. Plant Cell. 8(11), 19771989.

Purugganan, M.D., 1997. The MADS-box floral homeotic gene lineages predate the origin of seed plants: phylogenetic and molecular clock estimates. J. Mol. Evol. 45(4), 392-396.
Shore, P.,Sharrocks, A.D., 1995. The MADS-box family of transcription factors. Eur. J. Biochem. 229(1), 1-13.

Sung, S.K., Yu, G.H., Nam, J., Jeong, D.H., An, G., 2000. Developmentally regulated expression of two MADS-box genes, MdMADS3 and MdMADS4, in the morphogenesis of flower buds and fruits in apple. Planta. 210(4), 519-528.

Tapia-López, R., García-Ponce, B., Dubrovsky, J.G., GarayArroyo, A., Pérez-Ruíz, R.V., Kim, S.H., 2008. An AGAMOUS-related MADS-box gene, XAL1 (AGL12), regulates root meristem cell proliferation and flowering transition in Arabidopsis. Plant Physiol. 146(3), 11821192.

Theissen, G., Becker, A., Di Rosa, A., Kanno, A., Kim, J.T., Münster, T., Saedler, H., 2000. A short history of MADSbox genes in plants. Plant Mol. Biol. 42(1), 115-149.

Weigel, D., Meyerowitz, E.M., 1994. The ABCs of floral homeotic genes. Cell. 78(2), 203-209.

Weigel, D., Nilsson, O., 1995. A developmental switch sufficient for flower initiation in diverse plants. Nature. 377(6549), 495-500.

\section{How to cite this article:}

Wan, Y., Ye, J.-B., Wang, G., Zhang, W., Xu, F., Liao, Y., 2016. Molecular cloning and sequence analysis of MADS-box family gene (GbMADS6) from Ginkgo biloba L. Int. J. Curr. Res. Biosci. Plant Biol. 3(5), 73-79. doi: http://dx.doi.org/10.20546/ijcrbp.2016.305.011 